\title{
KOMPOSISI MAKANAN IKAN SEPAT SIAM (Trichopodus pectoralis Regan, 1910) DI DANAU TALIWANG, SUMBAWA
}

\section{DIET COMPOSITION OF SNAKESKIN GOURAMY (Trichopodus pectoralis Regan, 1910) IN TALIWANG LAKE, SUMBAWA}

\author{
Prawira.A.R.P. Tampubolon ${ }^{1}$ dan M.F. Rahardjo ${ }^{2}$ \\ ${ }^{1}$ Loka Penelitian Perikanan Tuna-Benoa \\ 2 Dosen pada Fakultas Perikanan Ilmu Kelautan-IPB
}

Teregistrasi I tanggal: 04 Januari 2013; Diterima setelah perbaikan tanggal: 24 Maret 2014; Disetujui terbit tanggal: 01 April 2014

Email: prawira.atmaja@yahoo.co.id

\begin{abstract}
ABSTRAK
Ikan sepat siam (Trichopodus pectoralis, Regan 1910) merupakan salah satu target penangkapan ikan di Danau Taliwang, Sumbawa. Penelitian ini bertujuan untuk mendeskripsikan komposisi makanan ikan sepat siam di Danau Taliwang. Pengambilan contoh ikan dilakukan pada bulan Mei-Juli 2010 menggunakan jaring insang. Analisis komponen makanan menggunakan indeks bagian terbesar. Total ikan contoh yang tertangkap selama penelitian sebanyak 110 ekor yang terdiri atas 59 ekor ikan jantan dan 51 ekor ikan betina. Panjang total ikan yang tertangkap berkisar antara 125-196 mm dan bobot antara 26,7-141,7 gram. Makanan ikan sepat terdiri atas mikroalga, Rotifera, Ostracoda dan serangga dengan makanan utama adalah mikroalga dari Kelas Bacillariophyceae (genera Melosira, Navicula, dan Diatoma). Komposisi makanan berdasarkan bulan pengamatan dan ukuran tubuh relatif sama.
\end{abstract}

\section{KATA KUNCI: Komposisi makanan, ikan sepat siam, Danau Taliwang}

\begin{abstract}
Snakeskin gouramy (Trichopodus pectoralis, Regan 1910) is a one of many target species of fish caught in Taliwang Lake, Sumbawa. The objective of this study is to describe the diet composition of snakeskin gouramy found in Taliwang Lake. The fish samples were caught using gillnet during May-July 2010. The diet composition was analyzed by using the index of preponderance. The total number of fish caught during the research was 110 fishes, comprising 59 males and 51 females. The range of total length and total weight of the samples were 125$196 \mathrm{~mm}$ and 26.7-141.7 grams, respectively. Snakeskin gouramy in Taliwang Lake mainly feed on Microalgae, Rotifer, Ostracod, and insect. Their main diet, however, is Microalgae from the class of Bacillariophyceae (genera of Melosira, Navicula, and Diatoma). The diet composition of the fish which was determined from the sampling time and body size is relatively the same.
\end{abstract}

KEYWORDS: Diet composition, snakeskin gouramy, Taliwang Lake

\section{PENDAHULUAN}

Danau Taliwang merupakan danau alami di Pulau Sumbawa telah ditetapkan sebagai Taman Wisata Alam (TWA) oleh Menteri Kehutanan dan Perkebunan pada tahun 1999 (Wahyuni \& Kurniawan, 2004). Selain sebagai obyek wisata alam dan wisata pemancingan, danau yang luasnya antara 584-913 hektar dan memiliki kedalaman rata-rata sekitar dua meter ini digunakan oleh penduduk lokal sebagai tempat mencari ikan (Purnomo \& Tjahjo, 2003). Salah satu ikan target tangkapan nelayan adalah ikan sepat siam yang aspek reproduksinya telah diungkapkan oleh Tampubolon \& Rahardjo (2011).

Ikan sepat siam bukanlah ikan asli Danau Taliwang, namun adalah ikan introduksi pada beberapa dasawarsa yang lalu. Saat ini, ikan sepat siam menjadi salah satu spesies yang sering tertangkap di sekitar tumbuhan air di Danau Taliwang. Kondisi ini berbeda dengan apa yang terjadi di Danau Toba, di mana penebaran sepat siam dianggap tidak berhasil (Syafei, 2005). Hal tersebut diperkuat oleh Siagian (2009) dan Wijopriono et al. (2010) yang tidak lagi menemukan ikan sepat siam di Danau Toba. Ketidakberhasilan introduksi ikan sepat siam juga terjadi di Waduk Ir. H. Djuanda (Kartamihardja, 2008).

Keberadaan ikan sepat di suatu perairan terkait dengan keberadaan tumbuhan air (Kartamihardja, 2008). Tumbuhan air yang menutupi $70-80 \%$ permukaan air di Danau Taliwang (Purnomo \& Tjahjo, 2003) mendukung perkembangan ikan sepat siam di danau ini. Tumbuhan air penting bagi ikan sepat siam pada saat bereproduksi. Ikan sepat siam memijah dengan membuat sarang (Asyari, 2007) dan meletakkan telurnya pada sarang yang ditempelkan di tumbuhan air. Selain aspek reproduksi, tumbuhan air juga berkaitan erat dengan proses ikan ini mencari makan.

Ketersediaan sumber daya makanan yang cocok merupakan salah satu faktor pendukung bagi populasi 
ikan sepat siam sukses berkembang di Danau Taliwang. Makanan merupakan komponen yang penting karena hal tersebut menentukan kualitas habitat dan berpengaruh pada penyebaran ikan di perairan (Hinz et al., 2005). Penelitian ini bertujuan untuk mendeskripsikan komposisi makanan sepat siam di Danau Taliwang.

\section{BAHANDANMETODE}

Penelitian ini dilaksanakan dari bulan Mei sampai Juli 2010 di daerah pinggiran Danau Taliwang, Sumbawa Barat,
Nusa Tenggara Barat yang terdapat banyak tumbuhan air (Gambar 1). Stasiun penelitian ditentukan berdasarkan pertimbangan karakteristik habitat dan efisiensi operasional pelaksanaan penelitian melalui informasi dari nelayan setempat berkaitan dengan lokasi banyak ditemukannya ikan sepat siam. Pengambilan contoh ikan dilakukan menggunakan jaring insang setiap dua minggu sekali. Contoh ikan diawetkan menggunakan formalin $10 \%$ dan dianalisis di Laboratorium Biomakro I, Departemen Manajemen Sumber Daya Perairan, Fakultas Perikanan dan Ilmu Kelautan, Institut Pertanian Bogor.

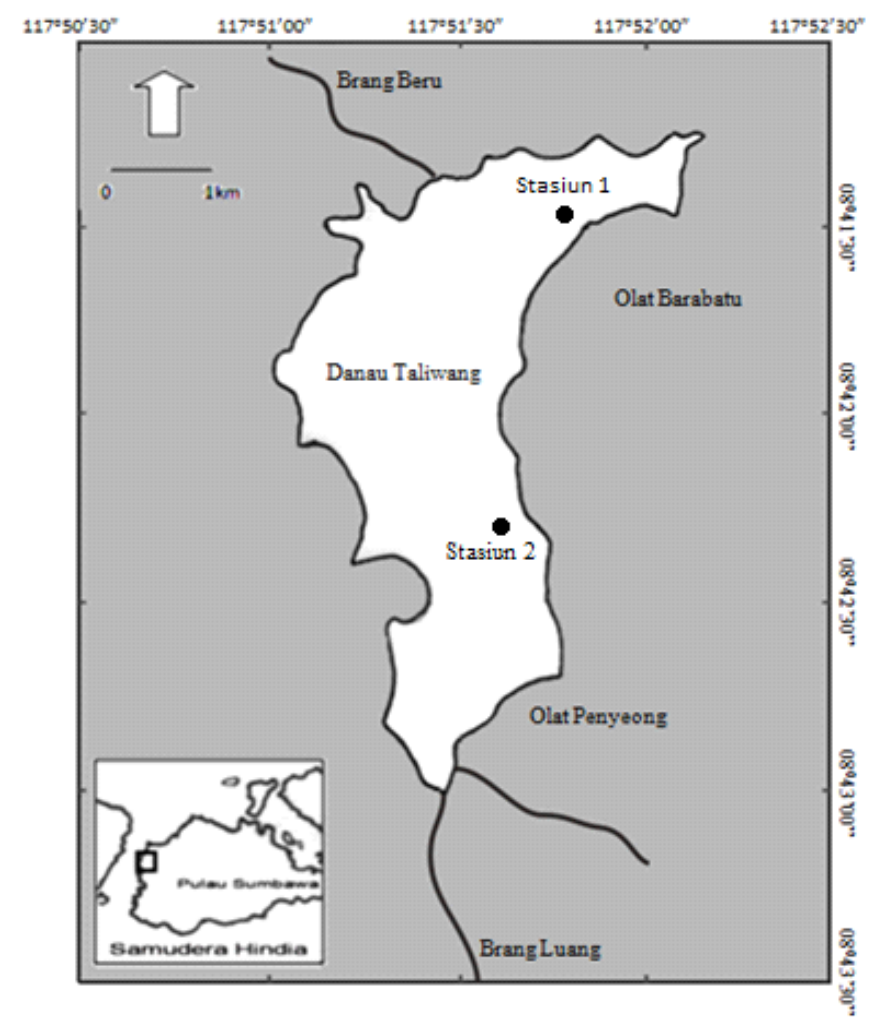

Gambar 1. Peta lokasi penelitian di Danau Taliwang, Sumbawa Figure 1. Sampling location at Taliwang Lake, Sumbawa

Ikan diukur panjang totalnya (TL) dan ditimbang bobotnya (W). Setelah itu ikan dibedah untuk menentukan jenis kelaminnya dengan cara mengamati gonad ikan. Selanjutnya saluran pencernaan dikeluarkan dari rongga perut. Ikan yang ususnya berisi kemudian dipisahkan menjadi dua kelas berdasarkan kisaran panjang total yaitu berukuran kecil (125-155 mm) dan besar (156-187 mm). Makanan ikan diidentifikasi sampai tingkat genera menggunakan acuan Davis (1955) dan Needham \& Needham (1962). Volume masing-masing organisme yang teridentifikasi diukur. Selanjutnya indeks bagian terbesar (Natarajan \& Jhingran, 1961) digunakan untuk menganalisis kebiasaan makanan dengan mengikuti persamaan:

$$
I_{i}=\frac{V_{i} \times O_{i}}{\sum\left(V_{i} \times O_{i}\right)} \times 100
$$

Keterangan:

$\mathrm{I}_{\mathrm{i}}=$ indeks bagian terbesar

$\mathrm{V}_{\mathrm{i}}=$ persentase volume jenis makanan ke $\mathrm{i}$

$\mathrm{O}_{\mathrm{i}}=$ frekuensi kejadian jenis makanan ke $\mathrm{i}$ 


\section{HASIL DAN BAHASAN}

\section{HASIL}

Lokasi penelitian merupakan daerah yang rapat dengan tumbuhan air. Tumbuhan air yang dominan pada lokasi penelitian adalah Eichhornia crassipes dan Nelumbo sp. Selama penelitian, ikan sepat siam yang tertangkap berjumlah 110 ekor ikan yang terdiri atas 59 ekor ikan jantan dan 51 ekor ikan betina. Kisaran panjang total dan bobot ikan adalah 125-196 mm dan 26,79-141,76 gram (Tabel 1).

Dari 110 ekor ikan, ditemukan 97 ekor ikan yang ususnya berisi. Organisme yang diidentifikasi sebagai makanan dalam saluran pencernaan ikan ini berasal dari jenis mikroalga, Rotifera, Ostracoda dan serangga (Gambar 2). Makrofita air yang ditemukan di dalam usus ikan sepat siam tidak diidentifikasi sebagai makanan. Makrofita yang merupakan tempat menempel makanan ikan sepat siam ini ikut termakan pada saat ikan makan. Komposisi makanan ikan sepat siam jantan dan betina relatif sama.
Mikroalga dan mikrofauna yang diidentifikasi dari saluran pencernaan ikan sepat siam berjumlah 35 genera dari 6 kelas (Tabel 2). Mayoritas genus yang ditemukan di saluran pencernaan ikan sepat berasal dari kelas Bacillariophyceae, diikuti Chlorophyceae, Rotifera, Cyanophyceae, Desmidiaceae, dan Ostracoda. Berdasarkan indeks bagian terbesar, selama penelitian, ikan sepat siam paling banyak mengkonsumsi mikroalga dari Kelas Bacillariophyceae.

Tiga jenis makanan yang paling banyak dikonsumsi ikan sepat berdasarkan waktu pengamatan adalah Diatoma, Melosira, dan Navicula (Tabel 3). Pada bulan Mei, ikan sepat paling banyak mengonsumsi Navicula $(17,73)$; Diatoma $(13,68)$ pada bulan Juni; dan Melosira $(13,42)$ pada bulan Juli.

Makanan yang paling banyak dikonsumsi oleh ikan sepat siam baik yang berukuran kecil maupun besar adalah mikroalga dari Kelas Bacillariophyceae berjenis Diatoma, Melosira, dan Navicula (Tabel 4) untuk ikan kecil dan besar. Ikan sepat siam kecil dan besar memanfaatkan sumber daya makanan yang relatif sama.

Tabel 1. Hasil tangkapan ikan sepat siam di DanauTaliwang, Mei-Juli 2010

Table.1 Results of snakeskin gouramy fishing at Taliwang Lake, May-July 2010

\begin{tabular}{lccccccccc}
\hline \multirow{2}{*}{$\begin{array}{l}\text { Mulan/ } \\
\text { Month }\end{array}$} & \multicolumn{3}{c}{ Jantan/Male } & \multicolumn{3}{c}{ Betina/Female } & \multicolumn{3}{c}{ Total } \\
\hline Mei/ May & $143-187$ & $50,36-107,50$ & 20 & $136-196$ & $41,98-141,76$ & 15 & $136-196$ & $41,98-141,76$ & 35 \\
Juni/ June & $125-165$ & $26,79-74,50$ & 17 & $130-160$ & $31,47-69,76$ & 14 & $125-165$ & $26,79-74,50$ & 31 \\
Juli/ July & $130-176$ & $30,27-89,19$ & 22 & $125-175$ & $29,36-97,26$ & 22 & $125-176$ & $29,36-97,26$ & 44 \\
\hline
\end{tabular}

Keterangan: PT: panjang total (mm); B: bobot (gram); n: jumlah (ekor)

Note: $\quad T L$ : total length $(\mathrm{mm}) ; \mathrm{W}$ : weight (gram); $n$ : frequency (individuals)

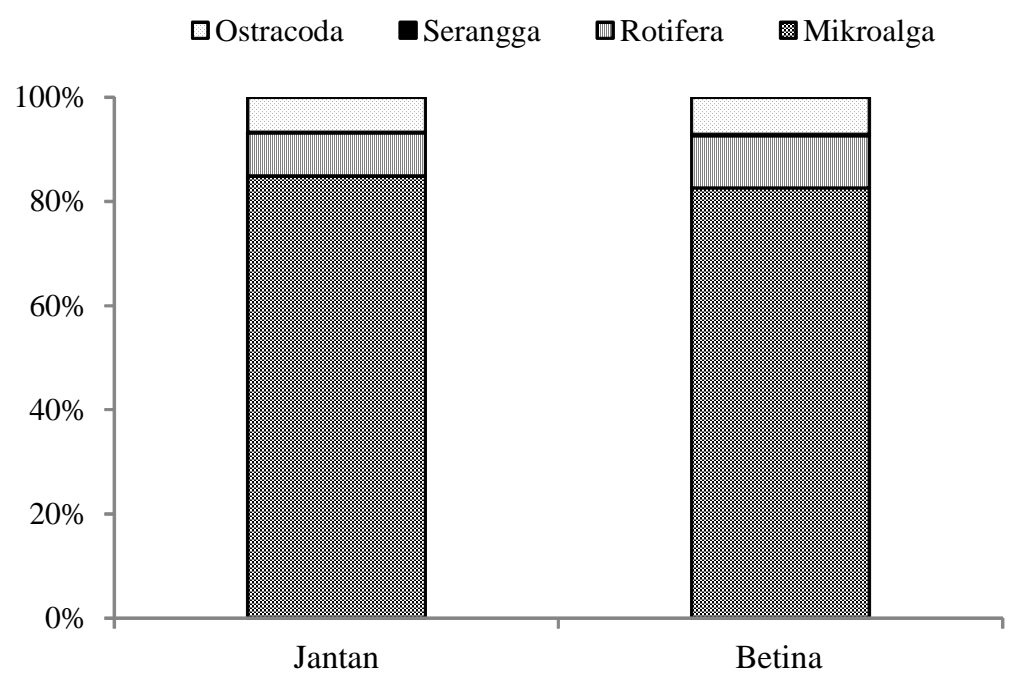

Gambar 2. Persentase masing-masing jenis makanan ikan sepat siam berdasarkan jenis kelamin

Figure 2. The percentage of the food categories found in the male and female snakeskin gouramy 
Tabel 2. Mikroalga dan mikrofauna yang menjadi makanan ikan sepat di Danau Taliwang

Tabel 2. Microalgae and microfauna which became the food of snakeskin gouramy in Lake Taliwang

\begin{tabular}{ll}
\hline \multicolumn{1}{c}{ Taksa/ } & \multicolumn{1}{c}{ Genera } \\
\hline Bacillariophyceae & Cymbella, Diatoma, Fragilaria, Frustulalia, Gyrosigma, Melosira, Navicula, \\
& Nitzchia, Pinnularia, Pleurosigma, Stauroneis, Surirella, Synedra \\
Chlorophyceae & Ankistrodesmus, Coelastrum, Microspora, Pediastrum, Scenedesmus, Spyrogira, \\
& Ulothrix, Zygnema \\
Cyanophyceae & Anabaena, Oscillatoria, Spirulina \\
Desmidiaceae & Closterium, Cosmarium, Gonatozygon, Straurastrum \\
Rotifera/ Rotifer & Epiphanes, Euchlanis, Keratella, Philodina, Synchaeta, Trichocerca \\
Ostracoda/Ostracod & \\
\hline
\end{tabular}

Tabel 3. Indeks bagian terbesar makanan ikan sepat berdasarkan bulan pengamatan

Table 3. Index of preponderance of snakeskin gouramy food based on sampling time

\begin{tabular}{llccc}
\hline No & Jenis makanan/ Food items & \multicolumn{3}{c}{ Bulan pengamatan/Sampling time } \\
& & & Juni/ June & Juli/ July \\
\hline \multirow{2}{*}{ Bacillariophyceae } & $\mathbf{6 5 , 2 8}$ & $\mathbf{5 0 , 4 6}$ & $\mathbf{4 4 , 4 6}$ \\
2 & Diatoma & 14,47 & 13,68 & 9,40 \\
2 & Melosira & 15,12 & 13,67 & 13,42 \\
3 & Navicula & 17,73 & 12,17 & 8,13 \\
4 & Frustulia & 10,07 & 2,34 & 1,28 \\
5 & Nitzchia & 1,94 & 5,19 & 3,66 \\
& Lainnya/ Others & 5,95 & 3,41 & 8,57 \\
& Chlorophyceae & $\mathbf{1 9 , 8 7}$ & $\mathbf{1 9 , 8 4}$ & $\mathbf{2 3 , 5 8}$ \\
6 & Ulothrix & 6,89 & 8,86 & 10,20 \\
7 & Spyrogira & 3,36 & 3,95 & 5,79 \\
8 & Scenedesmus & 2,90 & 2,07 & 4,54 \\
& Lainnya/ Others & 6,72 & 4,96 & 3,05 \\
& Cyanophyceae & $\mathbf{4 , 5 6}$ & $\mathbf{4 , 5 6}$ & $\mathbf{4 , 1 1}$ \\
9 & Oscillatoria & 3,51 & 3,39 & 3,62 \\
& Lainnya/ Others & 1,05 & 1,16 & 0,49 \\
& Desmidiaceae & $\mathbf{3 , 2 8}$ & $\mathbf{4 , 8 3}$ & $\mathbf{3 , 8 6}$ \\
10 & Closterium & 2,06 & 3,23 & 2,14 \\
& Lainnya/ Others & 1,23 & 1,59 & 1,72 \\
& Rotifera/ Rotifer & $\mathbf{5 , 5 8}$ & $\mathbf{1 0 , 6 1}$ & $\mathbf{1 1 , 2 5}$ \\
11 & Keratella & 3,57 & 5,75 & 6,25 \\
12 & Trichocerca & 1,34 & 3,24 & 2,63 \\
& Lainnya & 0,67 & 1,62 & 2,37 \\
13 & Potongan serangga/ Piece of insect & $\mathbf{0 , 1 2}$ & $\mathbf{0 , 1 4}$ & $\mathbf{0 , 2 3}$ \\
14 & Ostracoda/Ostracod & $\mathbf{1 , 3 0}$ & $\mathbf{9 , 5 7}$ & $\mathbf{1 2 , 5 1}$ \\
\hline \multicolumn{1}{|c}{ Total } & $\mathbf{1 0 0}$ & $\mathbf{1 0 0}$ & $\mathbf{1 0 0}$ \\
\hline & & & & \\
\hline
\end{tabular}

\section{BAHASAN}

Ikan sepat siam mencari dan mengonsumsi makanan yang ada di sekitar tumbuhan air. Hal ini terlihat dari ditemukannya Ostracoda pada proporsi yang relatif tinggi di saluran pencernaan ikan sepat siam pada penelitian ini. Ostracoda merupakan mikrokrustase yang bersifat sesil. Ostracoda dilaporkan menempel di tumbuhan air, misalnya akar eceng gondok (Eichhornia crassipes) (Marçal \& Calil, 2008). Hal yang senada juga dilaporkan pada ikan sepat layang. Sepat layang (Trichogaster leerii) dilaporkan mengonsumsi alga berfilamen yang menggunakan makrofita air sebagai substrat hidupnya (Zahid et al., 2009).

Ikan sepat siam di Danau Taliwang memanfaatkan mikroalga, rotifer, ostracoda dan serangga sebagai makanannya. Tidak ditemukan adanya perbedaan jenis makanan yang dikonsumsi oleh ikan sepat siam jantan dan betina. Ikan jantan dan betina mengonsumsi makanan yang relatif sama jenis dan jumlahnya (Gambar 2). 
Tabel 4. Indeks bagian terbesar makanan ikan sepat berdasarkan ukuran

Table 4. Index of preponderance of snakeskin gouramy food based on fish size

\begin{tabular}{|c|c|c|c|}
\hline \multirow{2}{*}{ No } & \multirow{2}{*}{ Jenis makanan/ Food } & \multicolumn{2}{|c|}{$\begin{array}{l}\text { Kelompok ukuran/ } \\
\text { fish size }\end{array}$} \\
\hline & & Kecil/small & $\begin{array}{c}\text { Besar/ } \\
\text { large }\end{array}$ \\
\hline & Bacillariophyceae & 59,97 & 47,26 \\
\hline 1 & Diatoma & 13,90 & 11,38 \\
\hline 2 & Melosira & 12,68 & 15,74 \\
\hline 3 & Navicula & 17,10 & 8,95 \\
\hline 4 & Frustulia & 5,93 & 2,31 \\
\hline \multirow[t]{3}{*}{5} & Nitzchia & 3,90 & 3,16 \\
\hline & Lainnya & 6,46 & 5,72 \\
\hline & Chlorophyceae & 17,29 & 25,80 \\
\hline 6 & Ulothrix & 5,25 & 12,64 \\
\hline 7 & Spyrogira & 2,60 & 6,45 \\
\hline \multirow[t]{3}{*}{8} & Scenedesmus & 4,15 & 2,46 \\
\hline & Lainnya & 5,29 & 4,25 \\
\hline & Cyanophyceae & 3,63 & 5,25 \\
\hline \multirow[t]{3}{*}{9} & Oscillatoria & 2,81 & 4,33 \\
\hline & Lainnya & 0,82 & 0,92 \\
\hline & Desmidiaceae & 4,24 & 3,79 \\
\hline \multirow[t]{3}{*}{10} & Closterium & 2,89 & 2,12 \\
\hline & Lainnya & 1,35 & 1,67 \\
\hline & Rotifera/ Rotifer & 8,06 & 10,55 \\
\hline 11 & Keratella & 5,26 & 4,37 \\
\hline \multirow[t]{3}{*}{12} & Trichocerca & 1,99 & 4,08 \\
\hline & Lainnya & 0,81 & 2,10 \\
\hline & $\begin{array}{l}\text { Potongan serangga/ } \\
\text { Piece of insect }\end{array}$ & 0,26 & 0,19 \\
\hline \multirow[t]{2}{*}{14} & Ostracoda/ Ostracod & 6,55 & 7,16 \\
\hline & Total & 100 & 100 \\
\hline
\end{tabular}

Mikroalga dari Kelas Bacillariophyceae adalah makanan utama ikan sepat siam. Tiga genera yang paling banyak dikonsumsi adalah Diatoma, Melosira, dan Navicula. Berdasarkan bulan pengamatan, ketiga genera tersebut secara bergantian, menjadi sumber daya makanan yang paling banyak dikonsumsi oleh ikan sepat siam. Kecenderungan dimakannya jenis yang sama oleh ikan sepat siam pada setiap bulan, menunjukkan bahwa Diatoma, Melosira, dan Navicula merupakan makanan utama ikan ini di Danau Taliwang. Di Waduk Darma, mikroalga yang paling banyak dikonsumsi ikan sepat siam adalah dari kelas Cyanophyceae dan Bacillariophyceae (Tjahjo et al., 2001); di Danau Arang-arang adalah dari Kelas Chlorophyceae dan Bacillariophyceae (Samuel et al. 2002); dan di Danau Tempe adalah dari Kelas Chlorophyceae dan Cyanophyceae (Samuel \& Makmur, 2012).

Fluktuasi proporsi dikonsumsinya Diatoma, Melosira, dan Navicula oleh sepat siam diduga karena perubahan ketersediaannya di alam. .Dugaan ini berangkat dari fakta bahwa perubahan kondisi perairan dapat mengakibatkan perubahan kelimpahan sumber daya pakan (Purnamaningtyas et al 2011; Nastiti \& Hartati 2013). Di Danau Tempe, mikroalga yang paling banyak dikonsumsi ikan sepat mengalami perubahan dari Synedra (Chlorophyceae) menjadi Anabaena (Cyanophyceae) (Samuel \& Makmur, 2012) terkait dengan perubahan ketersediaannya.

Berdasarkan perbedaan ukuran tubuhnya, tidak ditemukan adanya perbedaan makanan antara ikan berukuran kecil dan besar. Ikan sepat siam berukuran kecil dan besar memanfaatkan sumber daya makanan yang sama dengan komposisi yang relatif sama. Hal yang sama juga ditemukan pada ikan sepat mutiara dan sepat rawa (Zahid, 2008). Perubahan pemanfaaatan makanan sesuai perubahan ukuran tubuh umumnya terjadi pada ikan karnivora (Engin \& Seyhan, 2009; Chérif et al., 2011; Stagioni et al., 2011; Sšnchez-Hernšndez \& Cobo 2012). Pada ikan-ikan yang memakan mikroalga sebagai makanan utamanya, hal ini tidak berlaku (Gümü ${ }^{\circ}$ et al., 2002, Rahardjo et al., 2006; Asriyana et al., 2010).

\section{KESIMPULAN}

Ikan sepat siam memanfaatkan mikroalga Kelas Bacillariophyceae sebagai makanan utamanya. Bacillariophyceae yang paling banyak dikonsumsi adalah Melosira, Navicula dan Diatoma. Pemanfaatan sumber daya makanan oleh ikan sepat siam di Danau Taliwang relatif sama baik pada setiap bulan maupun berdasarkan ukuran panjang yang berbeda. Ikan Sepat siam merupakan ikan pemakan perifiton.

\section{PERSANTUNAN}

Penulis mengucapkan terima kasih kepada saudara Rahmat Mawardi, S.Pi yang telah membantu dalam pengumpulan ikan contoh.

\section{DAFTAR PUSTAKA}

Asriyana, M. F. Rahardjo., E. S. Kartamihardja \& D. F. Lumban Batu. 2010. Makanan ikan japuh, Dussumieria acuta Valenciennes, 1847 (Famili: Clupeidae) di perairan Teluk Kendari. Jurnal Iktiologi Indonesia. 10 (1). 9399.

Asyari. 2007. Pentingnya labirin bagi ikan rawa. Bawal. 1(5). 161-167.

Chérif, M., M. M. BenAmor, S. Selmi, H. Gharbi,H.Missaoui \& C. Capapé. 2011. Food and feeding habits of the red mullet, Mullus barbatus (Actinopterygii: Perciformes: Mullidae), off the northern Tunisian Coast (Central Mediterranean). Acta Ichthyologica Et Piscatoria.41 (2). 109-284. 
Davis, C.C. 1955. The marine and freshwater plankton. Michigan State University Press. USA. 526 p.

Engin, S \& K. Seyhan. 2009. Biological characteristics of rock goby, Gobius paganellus (Actinopterygii: Perciformes: Gobiidae), in the south-eastern Black Sea. Acta Ichthyologica et Piscatoria. 39 (2). 111-118.

Gümü A., M. Yilmaz \& N. Polat. 2002. Relative importance of food items in feeding of Chondrostoma regium Heckel, 1843, and its relation with the time of annulus formation. Turkish Journal of Zoology. 26. 271-278.

Hinz, H., I. Kroncke \& S. Ehrich. 2005. The feeding strategy of dab Limanda limanda in the Southern North Sea: Linking stomach contents to prey availability in the environment. Journal of Fish Biology. 67. 125-145.

Kartamihardja, E.S. 2008. Perubahan komposisi komunitas ikan dan faktor-faktor penting yang memengaruhi selama empat puluh tahun umur Waduk Djuanda. Jurnal Iktiologi Indonesia. 8 (2). 67-79.

Marcal, S.F \& C. T. Callil. 2008. Structure of invertebrates community associated with Eichhornia crassipes Mart. (Solms-Laubach) after the introduction of Limnoperna fortunei (Dunker, 1857) (Bivalvia, Mytilidae) in the Upper Paraguay River, MT, Brazil. Acta Limnologica Brasiliensia. 20 (4). 359-371.

Natarajan,A.V., \&A. G. Jhingran. 1961. Index of preponderance a method of grading the food elements in the stomach analysis of fish. Indian Journal. Fish. 8 (1). 54-59.

Nastiti, A.S., \& S. T. Hartati. 2013. Struktur komunitas plankton dan kondisi lingkungan perairan di Teluk Jakarta. Bawal 5 (3). $131-150$.

Needham, J.G., \& P. R. Needham. 1962. A guide to the study of freshwater biology. Holden Day, Inc. San Francisco. 107 p.

Purnamaningtyas, S.E., A. R. Syam, \& D. W. H. Tjahjo. 2011. Keanekaragaman plankton dan lingkungan perairan mangrove di daerah Mayangan, Subang, Jawa Barat. Bawal 3(5). 299-310.

Purnomo, K., \& D. W.H. Tjahjo. 2003. Beberapa aspek ekologi perikanan di Danau Taliwang, Nusa Tenggara Barat. Jurnal Penelitian Perikanan Indonesia. 9 (3). 21-26.

Rahardjo, M.F., M. Brojo, C.P.H. Simanjuntak, \&A.Zahid. 2006. Komposisi makanan ikan selanget, Anodontostoma chacunda HB 1822 (Pisces: Clupeidae) di perairan Pantai Mayangan, Jawa Barat. Jurnal Perikanan. 8(2). 159-166.
Samuel, \& S. Makmur. 2012. Karakteristik biologi beberapa jenis ikan introduksi di Danau Tempe, Sulawesi Selatan. In Kartamihardja ES et al. (editor). Prosiding Forum Nasional Pemacuan Sumber Daya Ikan III: KSI-26.

Samuel, S. Adjie, \& Z. Nasution. 2002. Aspek lingkungan dan biologi ikan di Danau Arang-arang, Propinsi Jambi. Jurnal Penelitian Perikanan Indonesia . 8 (1). 1-13.

Sšnchez-Hernšndez J, \&F. Cobo. 2012. Ontogenetic dietary shifts and food selection of endemic Squalius carolitertii (Actinopterygii: Cypriniformes: Cyprinidae) in River Tormes, Central Spain, in summer. Acta Ichthyologica et Piscatoria. 42(2). 101-111.

Siagian C. 2009. Keanekaragaman dan kelimpahan ikan serta keterkaitannya dengan kualitas perairan di Danau Toba, Balige, Sumatera Utara. [Tesis]. Sekolah Pascasarjana Universitas Sumatera Utara. Medan. 69 pp.

Stagioni M, S. Montanini , \& M. Vallisneri. 2011. Feeding habits of European Hake, Merluccius merluccius (Actinopterygii: Gadiformes: Merluccidae), From the Northeastern Mediterranean Sea. Acta Ichthyologica Et Piscatoria. 41 (4). $277-284$.

Syafei, L.S. 2005. Penebaran ikan untuk pelestarian sumber daya perikanan. Jurnal Iktiologi Indonesia. 5 (2). 69-75.

Tampubolon, P.A.R.P., \& M. F. Rahardjo. 2011. Pemijahan ikan sepat siam, Trichogaster pectoralis Regan 1910 di Danau Taliwang, Sumbawa. Jurnal Iktiologi Indonesia. 11(2). 159168.

Tjahjo, D.W.H., S. Nuroniah, \& S.E. Purnamaningtyas. 2001. Evaluasi bio-limnologi dan relung ekologi komunitas ikan untuk menentukan jenis ikan yang ditebar di Waduk Darma. Jurnal Penelitian Perikanan Indonesia .7 (1). 10-24.

Wahyuni, J.E., \& B. Kurniawan. 2004. Danau Taliwang, danau satu-satunya di Nusa Tenggara Barat. Warta Konservasi Lahan Basah. 12(4). 5.

Wijopriono., K. Purnomo, E. S. Kartamihardja, \&Z. Fahmi. 2010. Fishery resources and ecology of Toba Lake. Indonesian Fisheries Research Journal.16(1). 1-5.

Zahid A. 2008. Ekologi trofik ikan-ikan dominan (Trichogaster leerii, T. Trichopterus dan Rasbora dusonensis) di hutan rawa gambut Desa Dadahup, Kalimantan Tengah. [Tesis]. Sekolah Pascasarjana. Institut Pertanian Bogor. Bogor.

ZahidA, M. F. Rahardjo, S. Sukimin, \& L. S. Syafei. 2009. Variasi temporal makanan ikan sepat layang (Trichogaster leerii, Blkr. 1852) di hutan rawa gambut Desa Dadahup, Kalimantan Tengah. Berkala Penelitian Hayati. 15. 53-62. 